\title{
Sistem Informasi Pengendali Rincian Obyek Belanja Operasional Di Biro Hukum Kantor Gubernur Kalimantan Barat
}

\begin{tabular}{|c|c|}
\hline \multicolumn{2}{|c|}{ Dini Aljuniarti Putri ${ }^{1}$, Rabiatul Adwiya ${ }^{2}$, Latifah ${ }^{3}$} \\
\hline Info Artikel & ABSTRACT \\
\hline $\begin{array}{l}\text { Diterima Juli 10, } 2021 \\
\text { Revisi } \quad \text { Agustus 10, } 2021 \\
\text { Terbit } \quad \text { September 10, } 2021\end{array}$ & $\begin{array}{l}\text { Computers are equipment that was created to facilitate human work along } \\
\text { with developments in the world of work and technology that require fast- } \\
\text { paced. Currently, the Legal Bureau of the West Kalimantan Governor's } \\
\text { Office is doing manual recording with Ms. Excel media so that it is prone to } \\
\text { errors and takes a long time so it is hoped that the existence of this Shopping } \\
\text { Object Details Controlling Information System can simplify the detailing }\end{array}$ \\
\hline $\begin{array}{l}\text { Keywords: } \\
\text { Accounting System Information } \\
\text { Finance } \\
\text { State Spending }\end{array}$ & $\begin{array}{l}\text { system is the best solution to solve the problems that exist in this Legal } \\
\text { Bureau, and it is hoped that with a computerized system, an activity that is } \\
\text { more effective and efficient can be achieved in supporting the activities of } \\
\text { this Legal Bureau. The resulting system divides level access rights into } 2 \\
\text { users, namely access rights at the level of the Chair of the Finance } \\
\text { Subdivision and access rights at the Treasurer level of the Finance } \\
\text { Subdivision. Where each access level has its own limitations on the } \\
\text { applications made. The finance subdivision treasurer can view the final } \\
\text { report on operational expenditure expenditures, manage users, manage } \\
\text { operational expenditure transactions, manage types of operational } \\
\text { expenditure transactions, login and logout. Meanwhile, the head of the } \\
\text { finance sub-section can only log in and see the results of the spending control } \\
\text { report and logout. }\end{array}$ \\
\hline
\end{tabular}

\section{Identitas Penulis:}

Dini Aljuniarti Putri ${ }^{1}$, Rabiatul Adwiya ${ }^{2}$, Latifah $^{3}$

Universitas Bina Sarana Informatika

Jl. Abdurrahman Saleh No.18 A Pontianak,

Email: dinialjuniarti@gmail.com ${ }^{1}$, rabiatul.rba@bsi.ac.id ${ }^{2}$, latifah.lat@bsi.ac.id ${ }^{3}$

\section{PENDAHULUAN}

Teknologi informasi di dunia berkembang sangat cepat, sehingga mengakibatkan segala hal menjadi mudah tanpa batas. Perkembangan teknologi informasi saat ini berpengaruh pada penggunaan perangkat lunak yang selalu berkembang. Hampir setiap instansi, organisasi, perusahaan, lembaga baik milik pemerintah maupun swasta banyak menerapkan sistem komputerisasi atau sistem informasi guna mempermudah dan meningkatkan kinerja[10].

Peraturan Pemerintah Nomor 60 Tahun 2008 tentang Sistem Pengendalian Intern Pemerintah (SPIP) menjelaskan bahwa, pengendalian intern adalah sebuah proses yang integral pada tindakan dan kegiatan yang dilakukan secara terus menerus oleh pimpinan dan seluruh pegawai untuk memberikan keyakinan yang memadai atau tercapainya tujuan organisasi melalui kegiatan yang efektif dan efisien, keandalan pelaporan keuangan, pengamanan aset negara, dan ketaatan terhdap peraturan perundang-undangan.

Kantor Gubernur Kalimantan Barat merupakan Instansi Pemerintah yang semua lembaga pemerintah melaksanakan fungsi administrasi pemerintahan di lingkungan eksekutif baik di pusat maupun daerah temasuk komisi-komisi, dewan, badan yang mendapat dana dari APBN/APBD. Instansi adalah badan atau lembaga yang bertujuan untuk memberikan pelayanan pada masyarakat. Instansi pemerintah tidak berorientasi pada profit yang harus didapatkan. Modal yang digunakan instansi pemerintah berasal dari pajak, retribusi, atau subsidi. Selain itu, instansi pemerintah ini bertanggung jawab kepada lembaga legislatif dan masyarakat. Kantor Gubernur Kalimantan Barat Khususnya di Biro Hukum ini masih melakukan proses catatan belanja operasional mengunakan excel sehingga masih tidak terperincinya dana yang dikeluarkan dan dana sisa penggunaan belanja operasional.Sehingga dari permasalahan yang telah diuraikan diatas, maka 
perlu diimplementasikan Sistem Informasi Pengendali Rincian Obyek Belanja Operasionalonal Di Biro Hukum Kantor Gubernur Kalimantan Barat.

\section{METODE}

Metode pengumpulan data yang digunakan menggunakan adalah observasi, wawancara dan studi literature. Data yang telah dikumpulkan kemudian di olah untuk mengembangkan perangkat lunak sesuai dengan kebutuhan. Dalam Metode pengembangan perangkat lunak digunakan metode Model air terjun (waterfall) merupakan salah satu model dari metode pengembangan perangkat lunak mulai dari tahap analisa hingga pendukung system.

\section{HASIL}

Sesuai hasil analisa yang telah penulis lakukan pada Biro Hukum Kantor Gubernur Kalimantan Barat penulis menyimpulkan bahwa Sistem Informasi Pengendali Rincian Objek Belanja Operasional tergolong kurang baik dan kurang terperinci karna Sistem Pengendali masih belum tercatat dengan baik sehingga diperlukkannya suatu sistem Pengendali agar semua terkendali dengan baik dan sesuai. Adapun permasalahan pokok yang terjadi pada Biro Hukum Kantor Gubernur Kalimantan Barat sebagai berikut :

1. Kurangnya pengendali rincian dalam pencatatan Belanja operasional di Biro Hukum Kantor Gubernur Kalimantan Barat.

2. Sulit dalam pencarian data Belanja Operasional karna tumpukan data yang terlalau banyak.

3. Memerlukan waktu yang sangat lama dalam pencarian catatan

4. Kurangnya efisiensi dan efektifitas dalam pencatatan belanja operasional yang ada di Biro Hukum Kantor Gubernur Kalimantan Barat.

Berdasarkan masalah yng ditemukan, maka pemecahan masalah sebagai berikut :

1. Membangun perancangan sistem yang dapat membantu proses-proses pengendali rincian objek belanja operasional agar menjadi lebih terperinci

2. Mempermudah dalam pencarian data dengan menggunakan sistem yang terkendali dan terperinci

3. Mempersingkat waktu dalam perncarian data

4. Meningkatkan efisiensi dan efektifitas dalam pencatatan belanja operasional yang ada di Biro Hukum Kantor Gubernur Kalimantan Barat-

\section{Use Case Diagram}

Sumber : Hasil penelitian(2021)

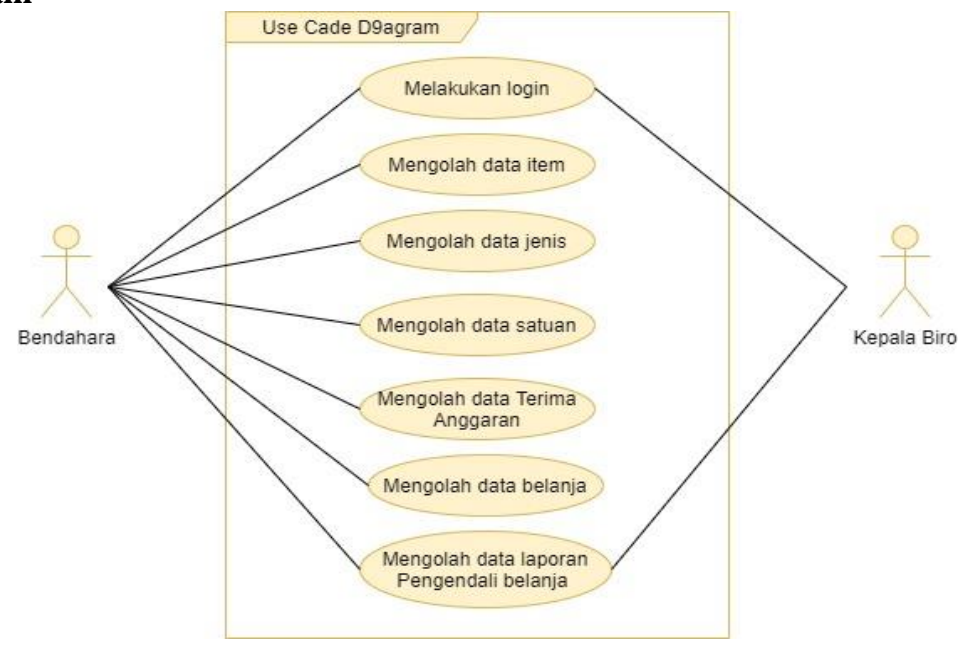

\section{Gambar 1 Use Case Diagram}

Use Case Diagram digunkan untuk mempermudah membaca hubungan dan alur dari actor atau orang yang berperan sebagai pengelola dan sistem yang dirancang. Berikut ini penjelasan atau deskripsi dari Use Case Diagaram diatas.

Pada gambar 1 menggambarkan Use Case Diagram dari aplikasi pengendali rincian objek belanja di Biro Hukum Kantor Gubernur Kalimantan Barat diman yang menjadi pengelola adalah bendahara biro hukum. Bendahara dapat mengelola Data Manter dan Data Transaksi sampai dengan Laporan pengendali belanja. 


\section{A. User Interface}

1. Form Login

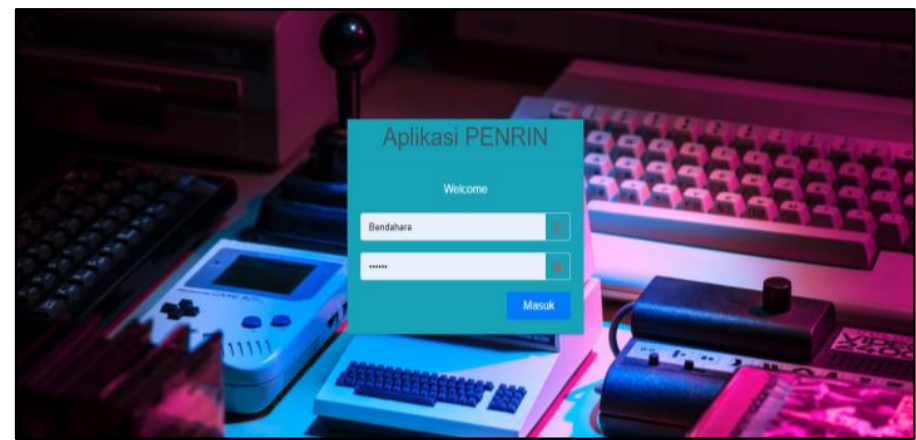

Sumber : Hasil Rancangan(2021)

Gambar 2. User Interface Halaman Login

Form login digunakan untuk setiap user yang masuk ke dalam sistem pegendalian Belanja. Form login dibuat untuk membatasi akses setiap user dalam mebuka form. User harus memasukkan Username dan Password yang telah terdaftar didalam sistem. jika password yang diisi salah, maka sistem akan menampilkan keterangan informasi password salah. Setelah melakukan login makan user akan diarahkan ke menu utama dan diberikan hak akses sesuai dengan hak akses masing-masing.

2. Form Home atau Profil

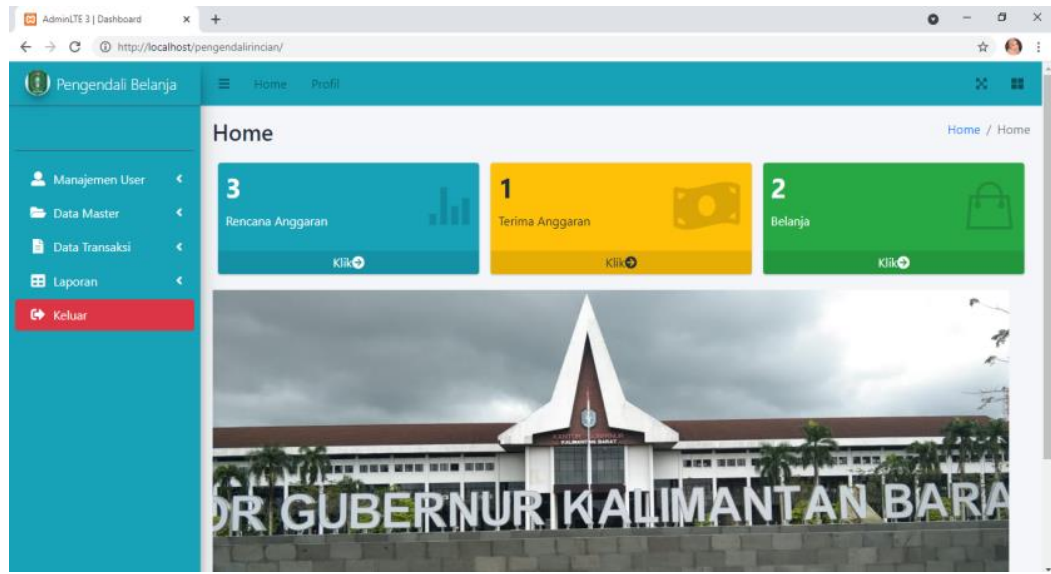

Sumber : Hasil Rancangan(2021)

Gambar 3. User Interface Halaman Beranda

Form ini merupakan tampilan utama atau beranda pada saat user telah login. Pada form beranda ini terdapat berbagai menu yang dapat menghubungkan user keberbagai form lainnya.

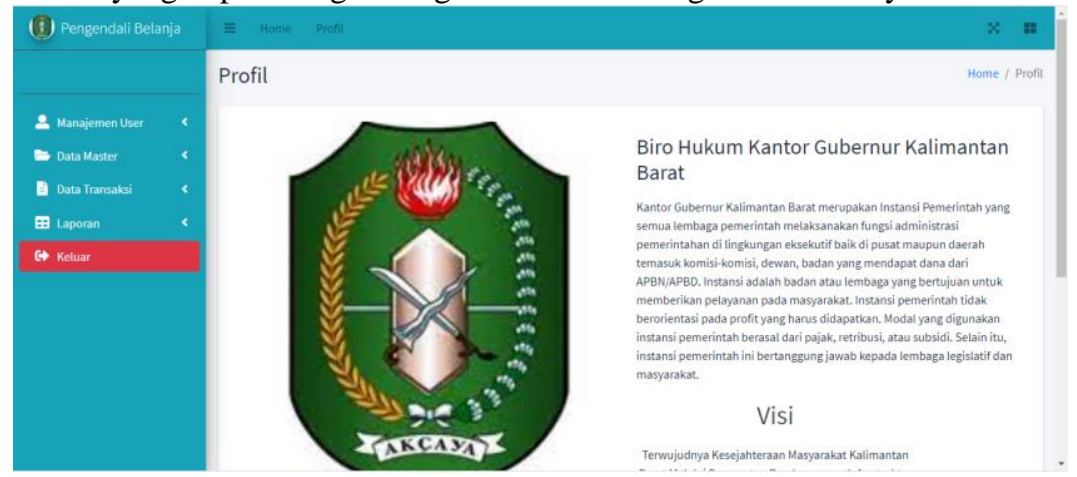

Sumber : Hasil Rancangan(2021)

Gambar 4 User Interface Halaman Profil

Form ini merupakan tampilan menu profil yang berisikan penjelasan singkat tentang Biro Hukum Kantor Gubernur Kalimantan Barat serta Visi dan Misi nya. 
3. Form Pengguna

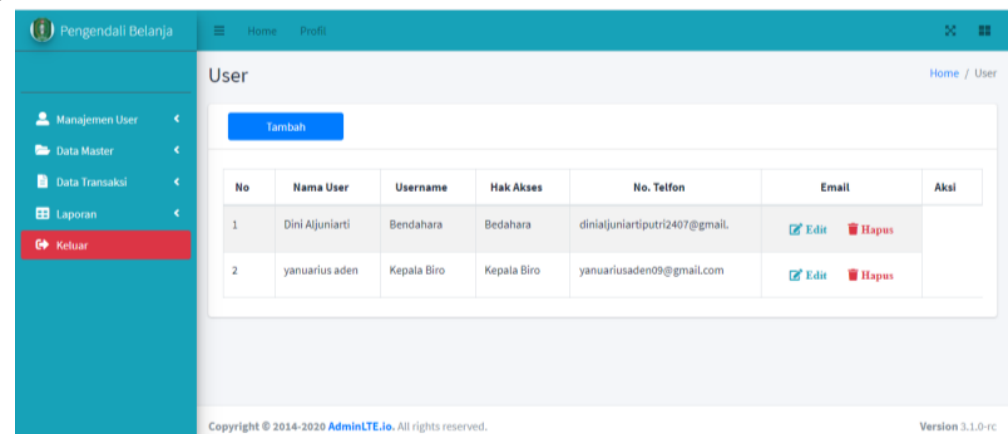

Sumber : Hasil Rancangan(2021)

Gambar 3. User Interface Halaman User

Form ini merupakan tampilan halaman user yang menampilkan siapa saja yang memiliki hak akses pada sistem ini.

4. Form Rencana Anggaran / item

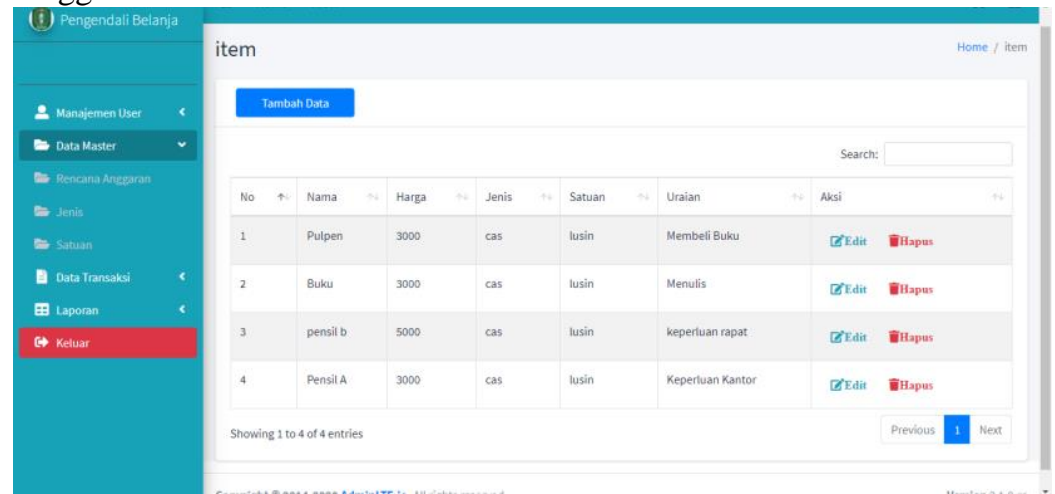

Sumber : Hasil Rancangan(2021)

\section{Gambar 4. User Interface Rencana Anggaran / Item}

Form ini menampilkan Rencana Anggaran yang berfungsi untuk membuat Rencana Anggaran yang berdasarkan Anggaran awal. Disini User dapat menginput rencana anggaran dengan meninput Nama, Harga, Jenis, Satuan dan Uraian setelah selesai melakukan penginputan user mengklik tombol simpan kemudian akan tampil Hasil inputan, dihalaman hasil penginputan user bisa melakukan tambah data, edit dan hapus.

5. Form Jenis

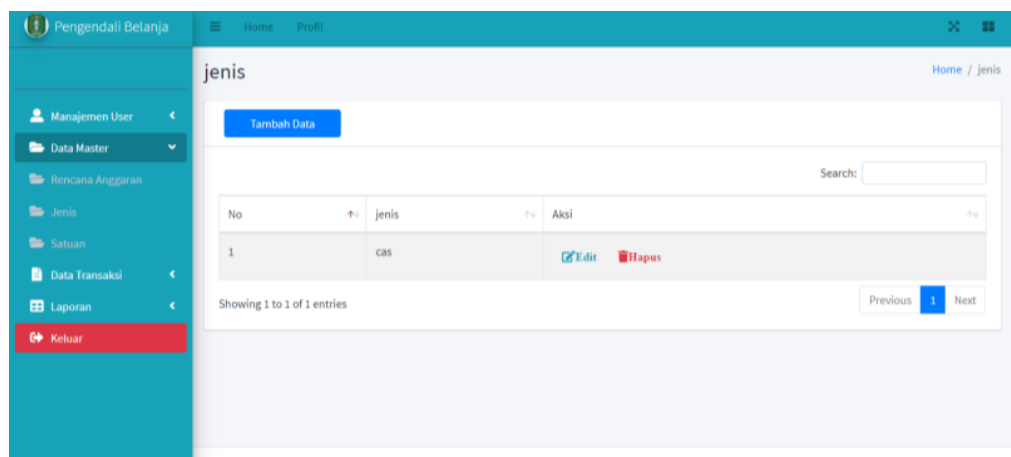

Sumber : Hasil Rancangan(2021)

Gambar 5. User Interface Halaman Jenis

Form ini menampilkan Halaman jenis yang berfungsi untuk menginput data Jenis. User dapat memilih jenis sesuai dengan ketentuan yang berlaku, kemudian mengklik tombol simpan. User juga dapat melakukan Edit dan Hapus.

6. Form Satuan 


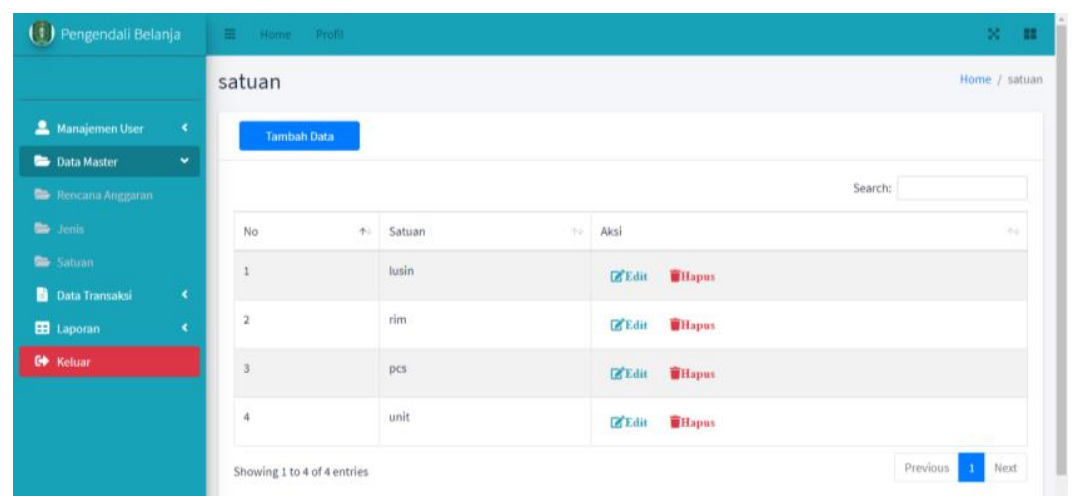

Sumber : Hasil Rancangan(2021)

\section{Gambar 6. User Interface Halaman Satuan}

Form ini menampilkan Halaman satuan yang berfungsi untuk menginput data Satuan. User dapat memilih Satuan sesuai dengan ketentuan yang berlaku, kemudian mengklik tombol simpan. User juga dapat melakukan Edit dan Hapus.

7. Form Terima Anggaran

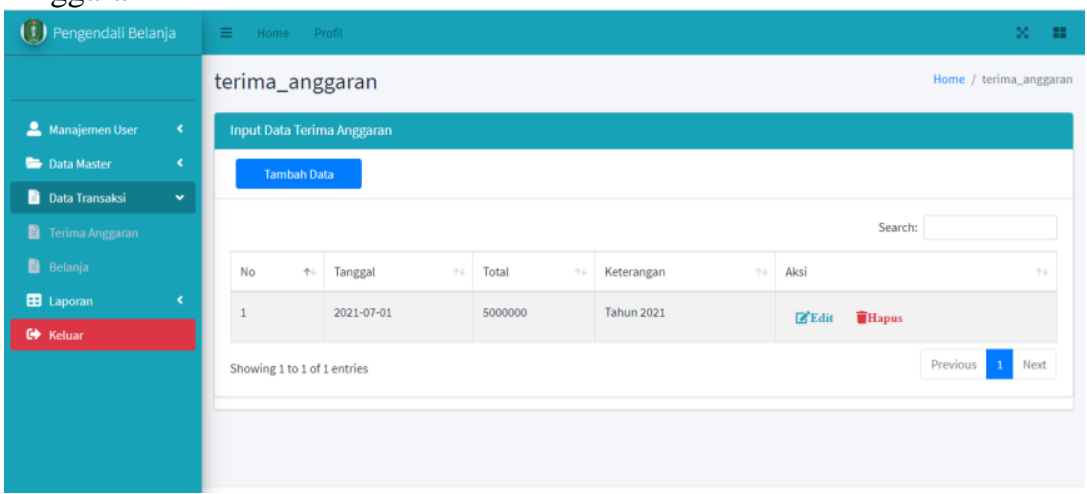

Sumber : Hasil Rancangan(2021)

Gambar 7. User Interface Terima Anggaran

Form ini menampilkan form Terima anggaran yang berfungsi untuk menginput anggaran yang diterima dengan cara menginput tanggal terima anggaran, Total anggaran yang diterima, Keterangan. Kemudian User mengklik tombol simpan. Setelah data berhasil disimpan user dapat melakukan Tambah Data, Edit dan Hapus.

8. Form Belanja

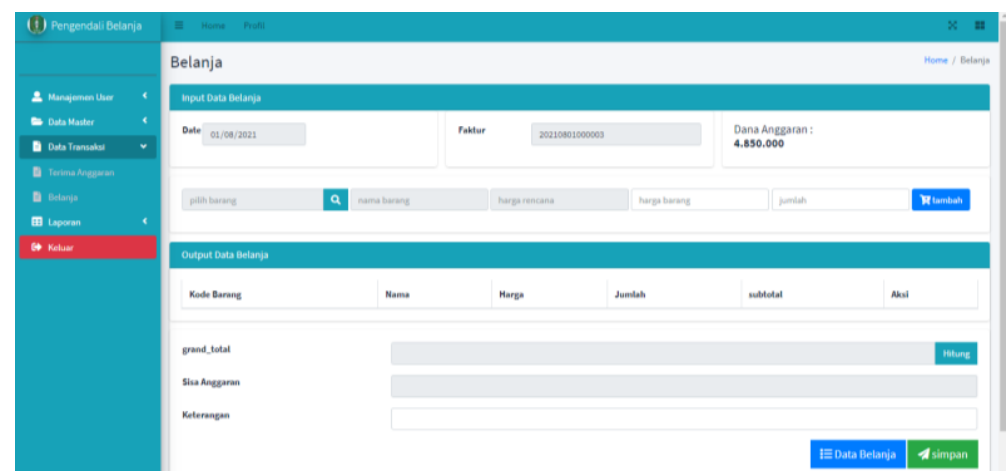

Sumber : Hasil Rancangan(2021)

Gambar 8. User Interface Halaman Belanja

Form ini menampilkan halaman belanja yang berfungsi untuk membuat transaksi belanja berdasarkan Rencana Anggaran. Disini User dapat melakukan transaksi dengan cara menginput nama barang, harga awal dan jumlah yang diperlukan kemudian klik tombol tambah. Setelah semua sudah diinput akan tampil hasil inputan yang berisikan nama barang, harga, jumlah dan subtotal. Pada menu grand total akan ada hasil transaksi kemudian mengklik tombol hitung dan akan muncul sisa anggaran dan keterangan belanja 
kemudian klik tombol simpan. Pada menu Transaksi belanja terdapat juga menu Data belanja yaitu menampilkan semua transaksi yang telah berhasil dilakukan.

9.Form Laporan Pengendali Belanja

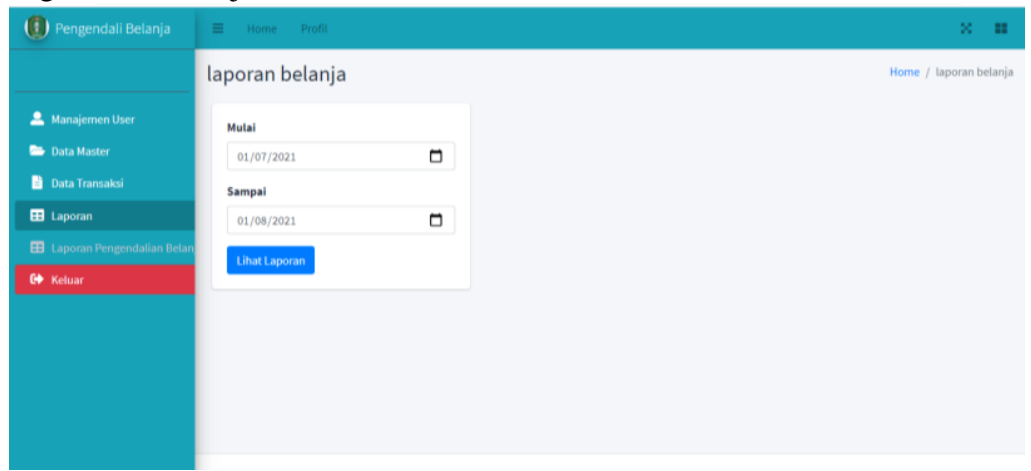

Sumber : Hasil Rancangan(2021)

Gambar 9. User Interface Halaman Pengendali Laporan

Form ini menampilkan halaman Pengendali laporan belanja yang berfungsi untuk menampilkan berapa jumlah transaksi belanja pada bulan tersebut dengan waktu tertentu. Disini user dapat memilih priode dari bulan berapa sampai bulan berapa sesuai dengan yang dibutuhkan.

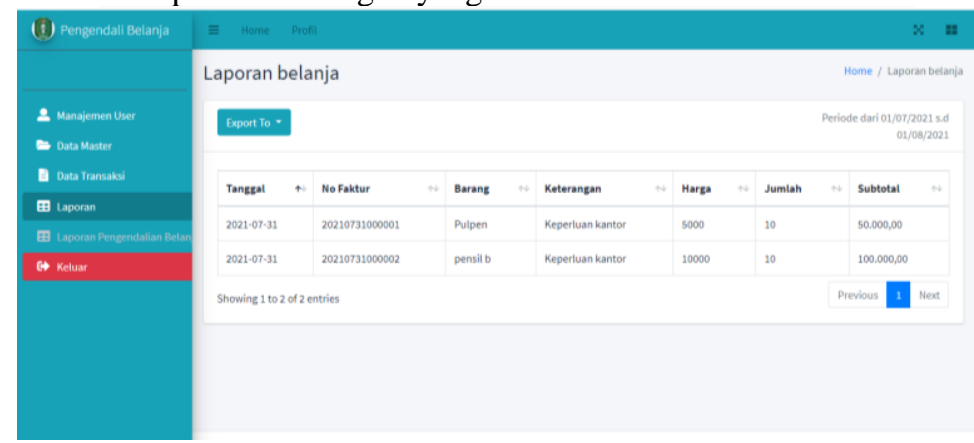

Sumber : Hasil Rancangan(2021)

Gambar 10. User Interface Laporan Belanja

Form ini Menampilkan Hasil Transaksi Belanja yang telah berhasil dilakukan. Disini user dapat melihat tanggal, no faktur barang, keterangan, harga, jumlah dan subtotal transaksi.

10. Tampilan Hasil Transasksi

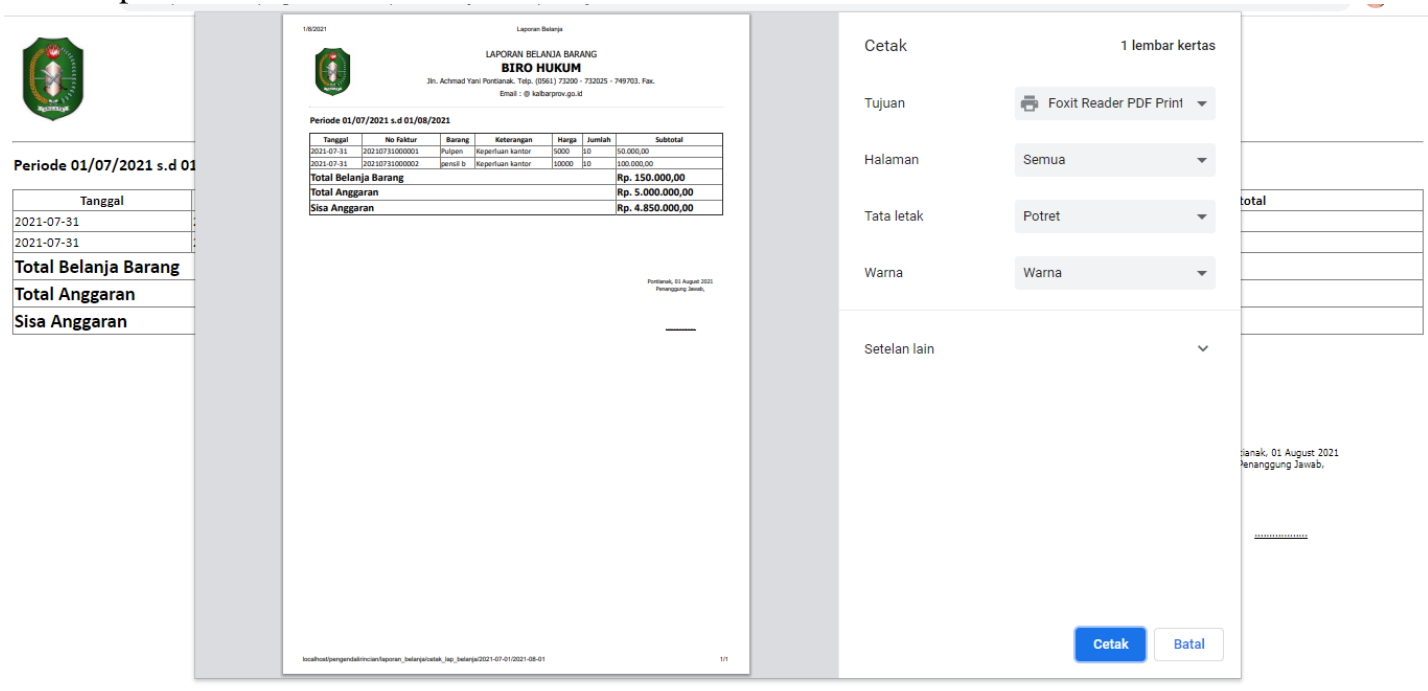

Sumber : Hasil Rancangan(2021)

Gambar 11 User Interface Output Laporan Pengendali Belanja 
Form ini menampilkan hasil cetakan Laporan Belanja yang berisikan tanggal, no faktur, nama barang, harga, jumlah, subtotal dan juga menampilkan Total belanja barang, Total anggaran, dan dapatlah sisa anggaran yang masih tersedia.

\section{KESIMPULAN}

Berdasarkan analisa yang telah maka disimpulkan bahwa :

a. Sistem pencatatan belanja operasionalonal masih manual menggunakan bantuan Ms.Excel sebagai mendia penyimpanan.

b. Permasalahan yang terjadi adalah kurangnya pengendali rincian dalam pencatatan Belanja operasional di Biro Hukum Kantor Gubernur Kalimantan Barat yang menyebabkan sulit dalam pencarian data serta memerlukan waktu yang sangat lama dalam pencarian catatan sehingga menyebabkan dirasakan kurang efektif dan efisien.

c. Dibuat sebuah sistem informasi akuntansi yang mampu mengolah data Pengendali Rincian Obyek Belanja Operasional Di Biro Hukum Kantor Gubernur Kalimantan Barat hingga menjadi laporan secara efektif dan efisien.

\section{UCAPAN TERIMA KASIH}

Terima kasih kepada Biro Hukum Kantor Gubernur Kalimantan Barat yang telah bersedia menjadi objek penelitian. Terima kasih juga kepada tim jurnal JUSTIAN yang telah menerbitkan artikel ini sehingga dapat dipublikasikan dan dibaca khalayak untuk dapat dijadikan referensi dan acuan penelitian selanjutnya.

\section{REFERENSI}

[1] Anggraeni, D., \& Irviani. (2017). RANCANG BANGUN SISTEM INFORMASI AKUNTANSI PENJUALAN BARANG BANGUNAN PADA TOKO BANGUNAN CAHAYA MUTIARA BALONGGANDU KARAWANG. Journal of Chemical Information and Modeling, 53(9), 1689-1699.

[2] Anna Mariana, Sentot Imam Wahjono, M. S. (2019). ANCANG BANGUN SISTEM INFORMASI AKUNTANSI PENDAPATAN JASA LAUNDRY PADA MENTARI LAUNDRY CIKAMPEK. Journal of Chemical Information and Modeling, 53(9), 1689-1699.

[3] Asmara, R., \& Alhamidi. (2017). Pengolahan data rehabilitasi penyalahgunaan narkoba pada klinik aqilah Payakumbuh. J-Click, 4(1), 74-83.

[4] Bekti. (2017). Adobe Dreamweaver CS6, CSS, dan Jqueryle. Adobe Dreamweaver CS6, CSS, Dan Jquery, 11.

[5] Fauzi. (2017). Rancang Bangun Sistem Informasi Akuntansi Pada Koperasi BMT NHDHATUL UMMAH Ciasem Subang. 6-18.

[6] Hermawan, W. (2017). Perancangan Program Penjualan Alat Musik Berbasis Web. Journal of Chemical Information and Modeling, 53(9), 1689-1699.

[7] Hutahaean. (2017). SISTEM INFORMASI AKUNTANSI PENERIMAAN PESANAN PENJUALAN PADA CV BINA USAHA MANDIRI KARAWANG. Journal of Chemical Information and Modeling, 53(9), 1689-1699.

[8] Infotek. (2018). RANCANG BANGUN SISTEM INFORMASI AKUNTANSI

[9] PENJUALAN BARANG SECARA TUNAI PADA DEPOT OSAMA BALONGGANDU JATISARI KARAWANG. Journal of Chemical Information and Modeling, 53(9), 1689-1699.

[10] Mailasari, Mely (2019). Sistem Informasi Perpustakaan Menggunakan Metode Waterfall. Jurnal Sistem Informasi dan Komputer 8(2), 207-214. https://doi.org/10.32736/sisfokom.v8i2.657

[11] Murni, S., Latifah, L., Sabaruddin, R., \& L, Y. (2019). Penerapanan Metode Waterfall Dalam Pembangunan Aplikasi Akuntansi Kontraktor Dengan Pemrograman Php. Jurnal Teknologi Informasi MURA, 11(1), 54-65. https://doi.org/10.32767/jti.v11i1.452

[12] Syafitri. (2019). PERANCANGAN SISTEM INFORMASI PENDAPATAN PASIEN BERBASIS WEB PADA PUSKESMAS FKTP SETUKFABKOT SUKABUMI MENGGUNAKAN NETODE WATERFALL. Journal of Chemical Information and Modeling, 53(9), 1689-1699. 